\title{
NUMERICAL MODELLING IN SEISMIC ANALYSIS OF TUNNELS REGARDING SOIL-STRUCTURE INTERACTION*
}

\author{
UDC 624.19:624.042.7=111
}

\section{Elefterija Zlatanović $^{1 \#}$, Gordana Broćeta ${ }^{2}$, Nataša Popović-Miletić ${ }^{2}$ \\ ${ }^{1}$ University of Niš, Faculty of Civil Engineering and Architecture, Serbia \\ ${ }^{2}$ University of Banjaluka, Faculty of Architecture and Civil Engineering, \\ Republic of Srpska, Bosnia and Herzegovina \\ \# elefterija2006@yahoo.com}

\begin{abstract}
The paper is related to the most significant aspects of numerical simulations in seismic analysis of tunnels, highlighting the soil-structure interaction phenomenon. The modelling of a problem and analysis of relevant influences may be completed by an application of software packages based on the finite element method. In order to define a reliable and efficient numerical model, that should simultaneously put together both the criteria of simplicity and realistic presentation of a physical problem, analyses should start from the most simple modelling techniques (theory of elasticity, replacing the soil medium with elastic springs, pseudo-static analysis), with the final goal to accomplish a more complex and realistic model (theory of elasto-plasticity, finite element method, full dynamic analysis).
\end{abstract}

Key words: tunnel, earthquake, soil-structure interaction, finite element model

\section{INTRODUCTION}

A simplified approach for the seismic design of tunnels is aimed to provide a tool for estimating the earthquake-induced stress increments in the tunnel lining [1]. Although it may be simple, it should be able to capture the most significant aspects of the seismic response of tunnels, including their lining and the surrounding ground, the seismic excitation should be properly represented, and the effects of dynamic soil-structure interaction should be properly accounted for. In order to apply the finite element method (FEM) concepts, certain assumptions and idealizations must be made. It is necessary to specify soil behaviour in the form of a mathematical constitutive relationship, as well as to simplify and/or idealize the geometry and/or boundary conditions of the problem. To a first ap-

\footnotetext{
Received December 5, 2013

* Acknowledgement: The authors gratefully acknowledge the support of the Ministry of Education, Science and Technological Development of Serbia within the Project TR36028 (2011-2014).
} 
proximation the transversal response may be considered to be uncoupled from the longitudinal response (i.e., the response along the direction of the tunnel axis).

\section{GEOMETRIC IDEALIZATION - 2D VS. 3D ANALYSIS}

Wave scattering and complex three-dimensional wave propagation can lead to differences in wave amplitudes along the tunnel, since ground motion incoherence tends to increase the strains and stresses in the longitudinal direction. Although the use of 3D methods to study dynamic soil-structure interaction under earthquake excitation has the appeal that some of the modelling errors are reduced, it suffers from the important disadvantages that the solution time and the complexity of the analysis are substantially increased. It is therefore necessary to make some rational approximations related to $2 \mathrm{D}$ analyses that may be performed within reasonable time period. Plane strain model in modelling three-dimensional tunnel structures should be adopted when they are uniform throughout their length (homogeneous surrounding medium, ground motion coherence, as well as continuous cast-in-place and straight-jointed segmented linings), or without considering deformation of the tunnel face and staggered-jointed lining rings.

In a $2 \mathrm{D}$ analysis there can be used plane strain and axi-symmetric approach depending on the desirable results. The plane strain approach can be used when analyzing shallow tunnels and the effects of the surface settlements, or to study the effects of tunnel construction on existing structures. In addition, the plane strain analyses can be used when transverse sections of multiple tunnels are modelled. The axi-symmetric approach is widely used for deep tunnels, when the surface settlements are not of prime interest or when the face advance is analyzed. Moreover, there are two methods of seismic response analysis, frequency domain analysis and time domain analysis.

\section{BOUNDARY CONDITIONS}

In infinite systems, wave that propagates to infinity does not bounce back to the soil (structure) model. In numerical simulations, attention is usually restricted to a finite region. Then an artificial boundary condition is needed to make the computational domain finite. In addition, for computational efficiency, it is desirable to minimize the number of elements in a finite-element analysis, by minimizing the size of the discretized region. As the size of the discretized region decreases, the influence of boundary conditions becomes more significant.

\subsection{Uniform ground vs. two-layered formation}

Under the assumption of uniform ground (infinite elastic or elasto-plastic space), the influence of ground surface is ignored. This approach is being used for deeply buried tunnel structures, considering P- and S-wave propagation. Since the overburden of the tunnel is too thick and the ground surface cannot be modelled, the outer boundaries should be located at distances several times the tunnel diameter (4-5D), which should be far enough from the tunnel such that the presence of boundaries does not affect the solution. It could result in reducing the errors of stresses up to several percent. 
Under the assumption of two-layered formation (semi-infinite elastic or elasto-plastic space), the influence of the ground surface is considered. This approach is being used for shallow embedded tunnel structures, in which case, beside $\mathrm{P}$ and $\mathrm{S}$ body waves, surface $\mathrm{R}$-waves have a significant contribution to the response of tunnel structures. The effect of the truncated soil medium is generally approximated by the artificial boundary such as a horizontal plane located under the bottom of the tunnel, at the bedrock along which the forces are being applied to the model. This boundary condition causes propagation of stress and strain waves upwards, due to which the tunnel stability against these stresses and strains should be estimated. In the case of two-layered formation (soft soil overlying bedrock), and vertically propagating shear waves, for determining maximum layer thickness to avoid filtering of relevant frequencies, following relation should be satisfied:

$$
H=\frac{C_{s}}{4 f_{\max }}
$$

where $C_{s}$ is the S-wave velocity of the soil layer, and $f_{\text {max }}$ is the natural frequency of the soil at which the strongest amplification occurs. The greatest amplification factor will occur at the lowest natural frequency, also known as the fundamental frequency.

\subsection{Simulation of rigid and elastic bedrock}

The boundary condition at the bottom of the soil deposit depends on the nature of the underlying bedrock that could be assumed as a rigid boundary or elastic boundary.

If the bedrock is rigid, its motion will be unaffected by motions in the overlying soil. It acts as a fixed-end boundary. Any downward-traveling waves in the soil will be completely reflected back toward the ground surface by the rigid layer, thereby trapping all of the elastic wave energy within the soil layer. In a time domain analysis, the rigid bedrock is simply modelled by imposing an acceleration (or velocity or displacement) time-history at the base of the numerical model (its particle acceleration can be specified directly as the input motion to the lower boundary of the FE mesh) [2].

If the bedrock is elastic, downward-traveling stress waves that reach the soil-rock boundary will be reflected only partially; part of their energy will be transmitted through the boundary to continue traveling downward through the rock and thus effectively removed from the soil layer. This is a form of radiation damping, and it causes the free surface motion amplitudes to be smaller than those for the case of rigid bedrock. In a time domain analysis, the presence of an elastic bedrock can be modelled by imposing a force time history rather than a base motion at the bottom of the soil layer (earthquake input motion cannot be imposed at viscous boundary). The continuity of the stresses along the rock-soil boundary requires that shear stress at the bottom of the soil layer be equal to the shear stress at the top of the rock. For this reason, the motion of an elastic bedrock is usually specified by adopting a shear stress time history $\tau(t)$ [3].

\subsection{Simulation of silent boundaries in infinite media}

For problems involving wave propagation analysis, the usual finite boundary of the finite element model will cause the elastic waves to be reflected and superimposed with the progressing waves. To avoid these reflections, it is necessary to impose a special 
condition on the restraining boundary, which is perfectly radiating to outgoing waves and transparent to incoming waves. Such boundary conditions have a variety of names, such as absorbing, silent, anechoic, non-reflecting, transmitting, radiating, transparent, or oneway boundary conditions.

The viscous damping boundary method (VDB) uses the concept of applying viscous dampers to the DOF on the boundary element. For an elastic media, such as soil, there are primary waves and secondary waves that travel through the media. Primary waves are compression waves that travel through solids, liquids, and gases. Secondary waves are shear waves that only travel through solids. The boundary condition is [4]:

$$
\begin{aligned}
& \begin{array}{lll}
\sigma_{z z}=a \rho V_{P} \dot{u}_{z} & \text { Primary wave } & V_{P}=\sqrt{\frac{E(1-v)}{(1-2 v)(1+v) \rho}}=\sqrt{\frac{M}{\rho}} \\
\tau_{z x}=b \rho V_{S} \dot{u}_{x} & \text { Secondary wave }
\end{array} \\
& \tau_{y z}=b \rho V_{S} \dot{u}_{y} \quad \text { Secondary wave } \quad V_{s}=\sqrt{\frac{E}{2(1+v) \rho}}=\sqrt{\frac{G}{\rho}}
\end{aligned}
$$

These equations are formulated for incident primary and secondary waves that act an angle $\theta$ from the z-axis as shown in Fig. 1. In the above equations, $\rho$ is a density, $G$ is a shear modulus, and $M$ is a constraint modulus of the media, $\dot{u}_{x}, \dot{u}_{y}, \dot{u}_{z}$ represent the velocities in the $\mathrm{x}, \mathrm{y}, \mathrm{z}$-direction, $V_{P}$ and $V_{S}$ are the velocities of the primary and secondary waves, and $a, b$ are relaxation coefficients. For small incident angles $\left(\theta<30^{\circ}\right)$, the most effective value for the dimensionless parameters $a$ and $b$ is 1.0.

The concept of the perfectly matched layers method (PML) [4] is designed to absorb thoroughly any incident wave without reflection, for any incident angle, and at any frequency before discretization. The main concept is to surround the computation domain at the infinite media boundary with a highly absorbing boundary layer, as shown in Fig. 2 . The objective of the PML method is to construct a new wave equation that creates plane waves that decay exponentially in the PML in the direction of the PML:

$$
\lambda_{i}=1-\mathrm{i} \gamma
$$

Here $\gamma$ is the attenuation in the PML region. This value will be zero in the computational domain. The complex coordinate stretching function $\lambda$ is continuous.

In the concept of infinite elements, the basic idea is to place elements with a special shape function for the geometry at the infinite boundary. Therefore, there will be two sets of shape functions, the standard shape functions $(\mathrm{N})$ and a growth shape functions $(\mathrm{M})$. The growth shape functions (M) grow without limit as coordinate approaches infinity, and are applied to the geometry. The standard shape functions $(\mathrm{N})$ are applied to the field variables. The geometry of the element (Fig. 3) is interpolated as [4]:

$$
x=M_{1} x_{1}+M_{2} x_{2} \quad M_{1}=-\frac{2 \xi}{1-\xi} \quad M_{2}=\frac{1+\xi}{1-\xi}
$$

This yields $x=x_{1}$ at $\xi=-1, x=x_{2}$ at $\xi=0$ and $x_{3}=\lim _{\xi \rightarrow 1} \frac{-2 \xi x_{1}+(1+\xi) x_{2}}{1-\xi}=\infty$. 


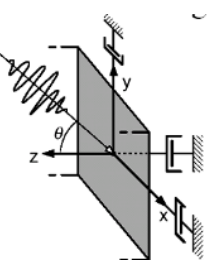

Fig. 1 Viscous Damping Boundary [4]

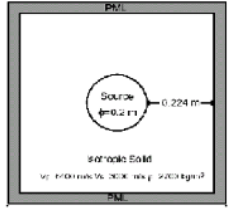

Fig. 2 PML surrounds the domain [4]

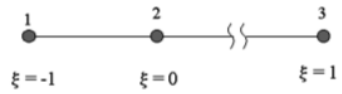

Fig. 3 Example of Infinite Element [4]

There are other solutions for silent boundaries: the energy transmission boundary, the roller boundary (under horizontal ground motion, the vertical fixed and horizontal free hinge bearings are being used), and the periodical boundary [5]. Special boundary conditions for wave propagation in saturated porous media are also proposed [6].

\section{DISCRETIZATION CONSIDERATIONS}

For plane strain conditions, the model is being discretized by triangular or quadrilateral finite elements, forming the FE unstructured or structured mesh. The mesh, on one hand, should be fine enough in order to accomplish more realistic results, but on the other hand, it should not be time and computational consuming due to a large number of nodes. A simple way to determine if the element size is fine enough to produce good results is by solving the problem with a certain number of elements and then comparing its results to the results of a model with twice as many elements. If a substantial difference between the results of the two models is detected, then the mesh refinement is necessary [7]. The finer mesh should be taken around the tunnel, where there are areas of highly stress concentration, in order to increase the accuracy of the analysis (Fig. 4).

In dynamic FEM analysis, the response of FE models can be influenced by discretization. In particular, the use of coarse finite-element meshes can result in the filtering of high-frequency components whose short wavelengths cannot be modelled by widely spaced nodal points. The maximum dimension of any element should be limited to one-eighth of the shortest wavelength considered in the analysis [8].

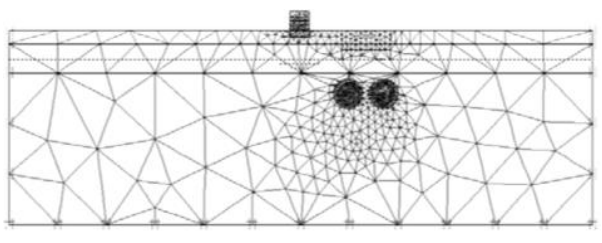

Fig. 4 Finite element mesh in numerical model - smaller elements in areas of high stress concentration

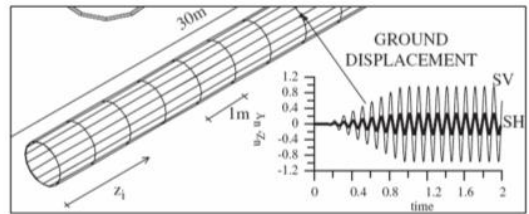

Fig. 5 Dynamically imposed displacements at a random node, for the uniform ground analysis [10]

\section{GROUND MOTION SIMULATION}

To obtain the acceleration time histories many options are available including artificial, spectrum-compatible accelerograms, synthetic records generated by a seismological model of 
the source, and real accelerograms (i.e., true records). The use of real accelerograms is preferred; however it is influenced by two problems: the lack of ground motion recordings indepth, and the difficulty to adequately scale the time-histories recorded at the free surface.

\subsection{Harmonic function of ground motion}

Harmonic loading is usually being used in order to understand fundamental characteristics of the dynamic behaviour of the tunnel, when the model is excited by sinusoidal waves $\left(\gamma=\gamma_{0} \sin \omega t, V=V_{0} \cdot e^{i \omega t}\right)$. After that, the analysis is followed by earthquake simulation as the exciting seismic waves [9].

When using a harmonic input to the model, according to recommendations of Kouretzis et al. [10], the buildup of ground motion should be gradual (Fig. 5), using a transition time interval equal to 8 wave periods, so as numerical pseudo-oscillations from the sudden application of a large amplitude displacement to be avoided.

\subsection{Real earthquake records}

In order to better simulate an earthquake, a real acceleration record should be taken as a dynamic input. Usually, two types of earthquake ground motions are being considered in the seismic response analysis of structures: an earthquake ground motion with a high probability of occurrence for structures in service, and an earthquake ground motion with a low probability but having a large acceleration. Recently, it is very often practice as the source of dynamic excitation the acceleration record for the 1995 Kobe, Japan earthquake to be used, as shown in Fig. 6, because this earthquake was the most devastating to civil infrastructure in recorded history.

The duration of strong ground motion can have a strong influence on earthquake damage. Many physical processes, such as the degradation of stiffness and strength of certain types of structures, and the buildup of pore water pressures in loose saturated sands, are sensitive to the number of load or stress reversals that occur during an earthquake. A motion of short duration may not produce enough load reversals for damaging response to build up in a structure, even if the amplitude of the motion is high. On the other hand, a motion with moderate amplitude but long duration can produce enough load reversals to cause substantial damage. The duration of strong motion increases with increasing earthquake magnitude.

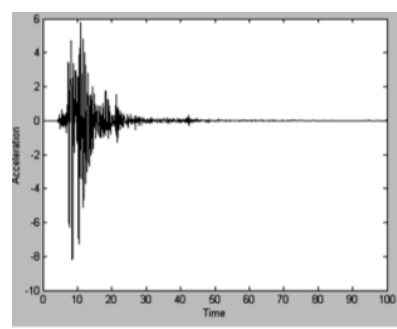

Fig. 6 Acceleration record of the 1995 Kobe Earthquake in Japan

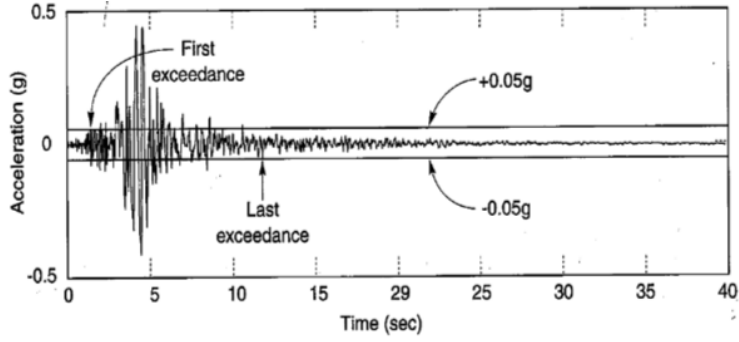

Fig. 7 The bracketed duration of an earthquake ground motion [3]

An earthquake accelerogram generally contains all accelerations from the time the earthquake begins until the time the motion has returned to the level of background noise. 
For engineering purposes, only the strong-motion portion of the accelerogram is of interest. To save on the computer CPU time, the recorded motion could be truncated before and after the certain periods. Different approaches have been taken to the problem of evaluating the duration of strong motion in an accelerogram. Because it implicitly reflects the strength of shaking, the bracketed duration is most commonly used for earthquake engineering purposes. The bracketed duration is defined as the time between the first and last exceedances of threshold acceleration (usually 0.05g) (Fig. 7).

\subsection{Synthetic records}

In the lack of real earthquake records, artificial ground motions must be developed. The main challenges in their development are to ensure that they are consistent with the target parameters (peak accelerations, velocities, or spectral ordinates) and that they are realistic. This is not as easy as it might appear; many motions that appear reasonable in the time domain may not when examined in the frequency domain, and vice versa. Many reasonable time histories of acceleration produce, after integration, unreasonable time histories of velocity and/or displacement. The methods for generation of artificial ground motions are [3]: (a) modification of actual ground motion records, (b) generation of artificial motions in the time domain, (c) generation of artificial motions in the frequency domain, and (d) generation of artificial motions using Green's function techniques.

The simplest approach is the modification of actual recorded ground motions. Maximum motion levels, such as peak acceleration and peak velocity, could be used to rescale actual strong motion records to higher or lower levels of shaking (Fig. 8). A desirable ground motion record will have not only a peak acceleration or velocity close to the target value, but also magnitude, distance, and local site characteristics that are similar to those of the target motion. Such a record is most likely to have a similar frequency content and duration to the target motion. Rescaling of the time scale may be used to modify the frequency content of an actual ground motion record. This is usually accomplished by multiplying the time step of a digitized actual record by the ratio of the predominant period $T_{p}$ (corresponding to the maximum value of the Fourier amplitude spectrum) of the target motion to the predominant period of the actual motion (Fig. 9).

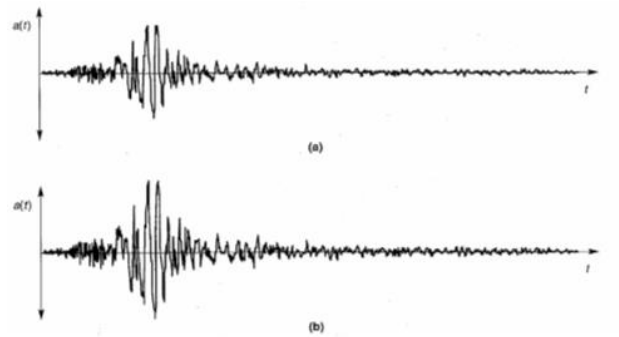

Fig. 8 (a) Original accelerogram from actual actual earthquake; (b) rescaled version of original accelerogram (accelerations scaled upward by a factor of 1.5 to match target peak acceleration) [3]

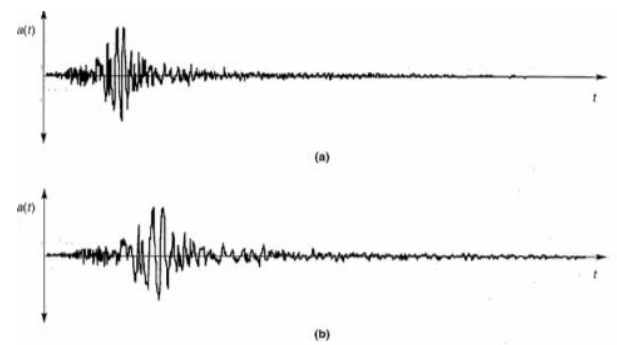

Fig. 9 (a) Original accelerogram from actual earthquake; (b) rescaled version of original accelerogram (time scale scaled upward by a factor of 1.3 to match target predominant period; the duration has also been increased by a factor of 1.3) [3] 


\section{Modelling Methods For SurRounding SoIL/RocK MEdium}

There are two basic approaches in modelling the soil/rock medium surrounding a tunnel structure: a spring supported approach (discontinuous model, discrete model) in the scope of conventional models, i.e., models based on subgrade reaction, and a FEM approach (continuous model).

\subsection{Beam-spring / shell-spring approach (bedded beam models)}

A spring model is used to express the interface between structure and soil, when a set of a structure and ground layers are simultaneously analyzed in order to evaluate the effects of soil-structure interaction (Fig. 10). In a seismic analysis, the interaction between the ground and the tunnel in plane strain conditions is being simulated by a coupled-type interaction spring consisting of a radial and tangential ground spring. Seismic forces acting on the beam-spring model can be assumed to be the product of ground displacements, ground shear stress, and inertial force, according to the Seismic Deformation Method (Fig. 11). The ground displacements are applied at the end of the ground springs, whereas the ground shear stresses are applied directly to the lining [9].

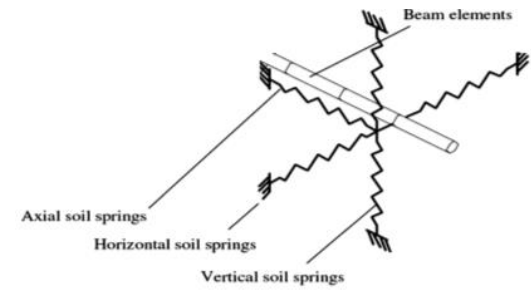

Fig. 10 Simplified three-dimensional beam-spring model for soil tunnel structure analysis

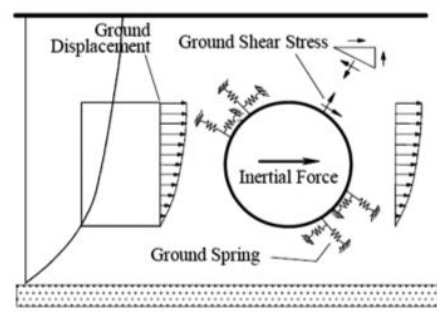

Fig. 11 Concept of the Seismic Deformation Method using beam-spring model

Linear (elastic) springs are used for the linear behaviour of the soil. In order to take into account the nonlinear behaviour of the soil, the use of nonlinear springs with bilinear elasto-plastic behaviour could be used, with an aim to add hysteretic damping to springs. A spring-dashpot model should be used when viscosity is considered; forces are generated due to the difference in velocity of the structure and the ground (Fig. 12).
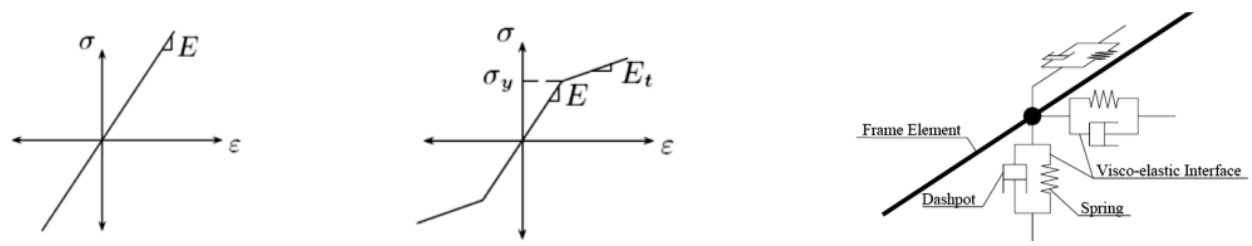

Fig. 12 Elastic spring, elasto-plastic spring, and Kelvin-Voigt elements

When using simple numerical models such as the beam-spring model, only a single structure can be accommodated in the analysis. They do not provide information on 
overall (global) stability or on movements in the adjacent soil, and ignore soil shearing transferring effects on adjacent structures and services.

\subsection{FEM approach (continuous soil models)}

One of the great benefits of numerical analysis to the tunnel engineer is that an analysis with FEM soil modelling can incorporate adjacent influences (existing surface structures, tunnels, etc.).

\subsubsection{Elastic soil models}

With regard to linear isotropic elasticity, an isotropic material is one that has point symmetry, i.e., every plane in the body is a plane of symmetry for material behaviour. Only two independent elastic constants are necessary to represent the behaviour. In structural engineering it is common to use Young's modulus, $E^{\prime}$, and Poisson's ratio, $\mu^{\prime}$. For geotechnical purposes, it is often more convenient to characterize soil behaviour in terms of the elastic shear modulus, $G$, and effective bulk modulus, $K^{\prime}$.

Soil/rock rarely behaves as a linear elastic material. The simplest approach would be to model them as a nonlinear elastic material. Two methods may be used to construct a nonlinear elastic stress-strain relation. They are known as Green's hyperelastic theory and hypoelastic theory. There are: the bi-linear model, $\mathrm{K}-\mathrm{G}$ model, and the Dancan-Chang hyperbolic model [11]. Nonlinear elastic models, in which the material parameters vary with stress and/or strain level, are a substantial improvement over their linear counterparts. Due to the number of parameters involved, most nonlinear elastic models assume isotropic behaviour. However, they still fail to model some of the important facets of real soil behaviour. They cannot reproduce the tendency to change volume when sheared. Also, because of the inherent assumption of coincidence of principal incremental stress and strain directions, they cannot accurately reproduce failure mechanisms.

\subsubsection{Equivalent-linear soil models}

Experimental results have suggested some energy to be dissipated even at a very low strain level, thus indicating that the damping ratio of a soil is never zero. It is also suggested that both the soil shear modulus and the damping ratio are dependent on the shear strain level. To describe the degradation of the shear modulus and the increase of the damping ratio along with the shear strain level increase, different curves were proposed in the literature for various types of soils [3]: fine-grained soils, sand, and gravel (Fig. 13). These are equivalent linear soil models that represent only an approximation of the actual nonlinear behaviour of the soil. For that reason they are not proposed to be used directly for problems concerning permanent ground deformation or failure, because they imply that the strain always returns to zero after the cyclic loading. Consequently, since a linear material has no limiting strength, it is not possible to achieve the soil failure. And yet, the assumption of linearity allows a very efficient class of constitutive models to be used for ground response analyses, particularly for problems involving low strain levels such as stiff soil deposits and weak input motions. 

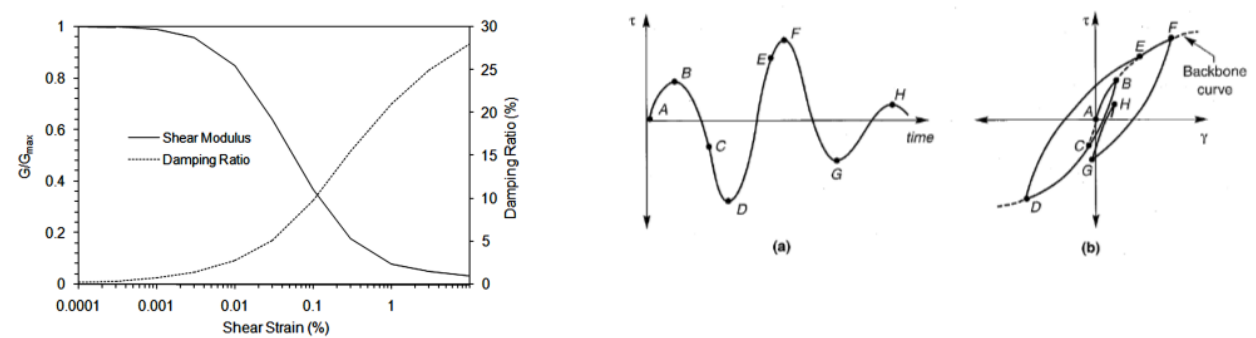

Fig. 13 Equivalent-linear model for Fig. 14 Cyclic nonlinear soil model: sand after Seed and Idriss [12]

(a) variation of shear stress with time;

(b) resulting stress-strain behaviour

(backbone curve indicated by dashed line) [3]

\subsubsection{Cyclic nonlinear soil models}

The nonlinear behaviour of soils can be represented more accurately by cyclic nonlinear models that follow the actual stress-strain path during cyclic loading. They are characterized by a backbone curve, rules that govern unloading-reloading behaviour, stiffness degradation, and many other effects (Fig.14). A variety of cyclic nonlinear soil models has been proposed [3]: the hyperbolic model, the modified hyperbolic model, the Ramberg-Osgood model, the Iwan-type model, the nonlinear hysteretic model - Iwan and Mroz IM model, the Martin-Davidenkov model, the Cundall-Pyke model, the HardinDrnevich-Cundall-Pyke model (HDCP), etc. Hashash and Park [13] introduced an extension of the modified hyperbolic model to capture the dependence of shear modulus degradation and damping curves on the confining pressure.

\subsubsection{Elasto-plastic soil models}

The most accurate and general methods for representation of soil behaviour are based on elasto-plastic soil models. These models use the basic principles of mechanics to describe the true soil behaviour under initial stress conditions, a wide variety of stress paths, rotating principal stress axes, monotonic or cyclic loading, low or high strain levels, and undrained or drained conditions. They are characterized by a yield surface that represents the limiting stress conditions, a hardening/softening law that describes changes in the size and shape of the yield surface along with an occurrence of plastic deformation, and a flow rule that relates plastic strain increments to stress increments. The simplest of these models are simple elasto-plastic models (Fig. 15) such as: the Tresca (1864) and von Mises models for cohesive soils, the Mohr-Coulomb and Drucker-Prager (1952) models for cohesive frictional soil or rock, the Hoek-Brown model (1980) for rock masses, the LadeDuncan model (1975), and the Matsuoka-Nakai model (1974, 1982) [11, 14]. More complex advanced constitutive models are critical state models that incorporate the Cam-clay (1963) and modified Cam-clay (1968) models for cohesive soils [11], as well as the CASM model for both clay and sand [14]. The most complex are advanced elasto-plastic models with multiple yield and plastic potential surfaces: the Lade's double hardening model, the MIT-E1 and MIT-E3 soil models, and the bubble models [11]. Advanced con- 
stitutive models allow significant generality and flexibility in simulating the response of soils under cyclic loading conditions. Nevertheless, for their description many more parameters than needed for the equivalent linear or cyclic nonlinear models are usually required. Evaluation of these parameters can be quite complex, and their values obtained from one type of test can considerably differ from those obtained from another. Although the application of advanced constitutive models has undoubtedly been increased, these practical issues have so far limited their use in geotechnical earthquake engineering practice.
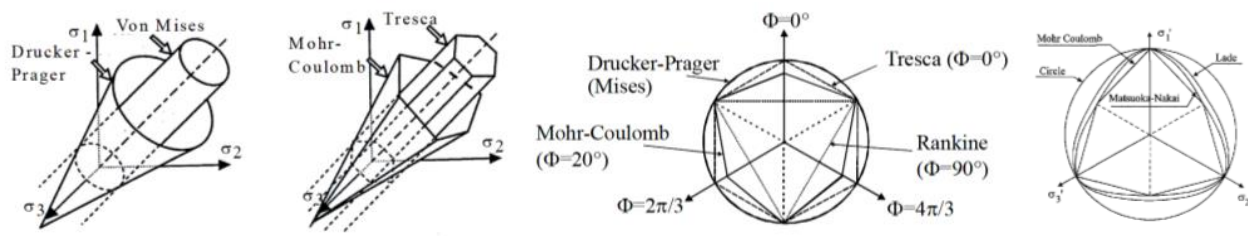

Fig. 15 Comparison of simple elastic perfectly plastic models [11]

\section{SOIL DAMPING FORMULATION}

The frequency domain (FD) solution of wave propagation provides the exact solution when the soil response is linear. For a linear elastic material, the area bounded by stress-strain loops is zero and then, there is no hysteretic damping. However, laboratory tests have clearly shown the presence of damping at very small strains, too. Numerically, this problem can be overcome by introducing viscous dashpots embedded within linear elastic elements. Soil behaviour is approximated as a Kelvin-Voigt solid.

Homogeneous linear visco-elastic layer the wave equation becomes independent of frequency for a harmonic loading with a circular frequency $\omega$. Since the solution for an arbitrary loading is performed by transforming the motion into a finite sum of harmonic motions using the Fourier transform, the damping of the system becomes independent of the frequency of the input motion due to the frequency independent viscosity:

$$
\eta=\frac{2 G}{\omega} \xi
$$

1. If the viscosity $\eta$ is constant, amplification function will have only finite number of peaks, corresponding to those natural frequencies of the layer which have damping less than critical. A critical value of viscosity can be established for each particular mode:

$$
\eta<\frac{4 H}{(2 n-1) \pi} \sqrt{G \rho}, \mathrm{n}=1,2, \ldots
$$

Constant value of viscosity corresponds to an increasing percentage of damping $\xi$ in each mode, meaning that the amplitude of the peak at the second natural frequency of the layer will be $1 / 9$ of that at the first, the amplitude at the third will be $1 / 25$, etc. (Fig. 16, left).

2. If it is assumed that viscosity is inversely proportional to the frequency, so that $\eta \omega /(2 G)$ is constant, it corresponds to constant damping $\xi$ in all modes. In this case, the amplitude of second peak will be $1 / 3$ that of the first, the amplitude of the third peak $1 / 5$, and so on (Fig. 16, right). 

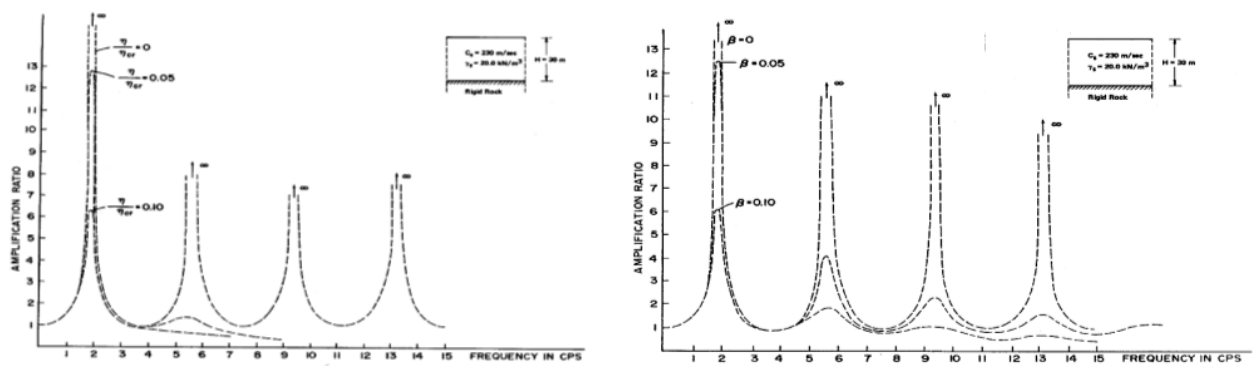

Fig. 16 Amplification curve for uniform layer over rigid rock:

(left) constant viscosity; (right) constant modal damping [15]

In nonlinear analysis, the dynamic equation of motion is integrated in the time domain (TD) and the nonlinear soil behaviour can be accurately modelled. Soil damping is captured primarily through the hysteretic energy dissipation. Viscous damping, using the Rayleigh damping formulation, is often added to represent damping at very small strains where many soil models are primarily linear. The Rayleigh damping formulation results in frequency dependent damping, in contrast to experiments that show that the damping of soil is mostly frequency independent. An appropriate choice of frequency range is needed.

Early Rayleigh formulations used a simplified form of the damping matrix, which is only stiffness proportional and depends only on the first mode of the deposit:

$$
[C]=\beta_{R}[K]
$$

where $\beta_{R}=2 \xi / \omega_{1}$ and $\omega_{1}$ is the frequency of the first natural mode of the soil column. The contribution of higher modes is small for relatively short soil columns, but may become important for deeper soil columns and for high frequency motion [16].

Conventional Rayleigh formulation $(C R F)$ is a double frequency method. In the original damping formulation proposed by Rayleigh and Lindsay in 1945, the [C] matrix is assumed to be proportional to the mass and stiffness matrices:

$$
[C]=\alpha_{R}[M]+\beta_{R}[K]
$$

It is a common practice to choose frequencies that correspond to the first mode and the second mode of the soil column, or the first mode of the soil column and a higher mode that corresponds to the predominant frequency of the input motion. This formulation may underestimate or overestimate the ground motion response at high frequencies, and the accuracy of solution deteriorates with an increase in depth of soil column [17].

In Rayleigh formulation $(R F)$, the performance of the double frequency RF analysis is improved by a different selection of the two significant frequencies. They should be selected in part to cover the range of significant frequencies in the input motion.

Equation (8) can be extended, so that more than two frequencies/modes (usually four) can be specified, and is referred to as extended Rayleigh formulation (ERF) [17]. The effective damping is illustrated in Fig.17, assuming the damping ratios are equal at the selected frequencies/modes. 


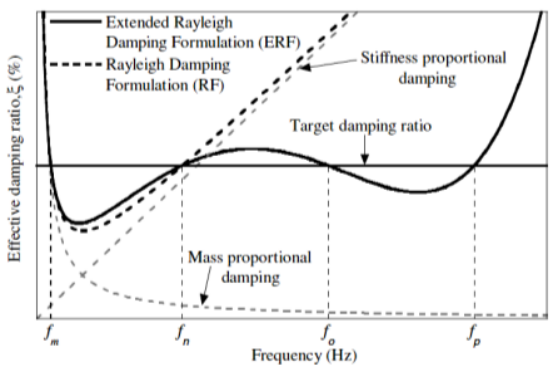

Fig. 17 Effective (frequency dependent) damping using RF and ERF damping formulations [17]

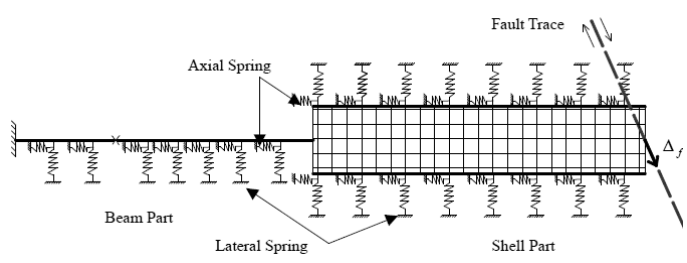

Fig. 18 Hybrid beam-shell FEM model [21]

\section{MODELLING THE TUNNEL LINING}

Tunnels linings are composed by materials which are more uniform than the ground, and are mostly assumed elastic [18]. In addition, in soil-structure interaction analysis, one of key influential parameters is a stiffness of a tunnel lining [1].

\subsection{Continuous cast-in-place tunnel lining}

This section is listing possibilities for suitable FE modelling of a tunnel lining composed of conventional concrete or self compacting concrete (SCC) [19]. Using solid elements has a significant drawback as the need to maintain an acceptable element shape (defined by the aspect ratio of length to width). A tunnel lining is likely to be very thin relative to the tunnel diameter and boundary distance. Moreover, this option cannot reveal the distribution of bending moments, axial and shear forces. There is a possibility to use structural elements. The beam model can be based on Bernoulli-Euler theory and Timoshenko beam theory. Shell elements are appropriate to be used where the structure is in presence of the membrane stress combined with bending stresses. The shells can be conventional or continuum ones. In the case of underground structures at crossings with active strike-slip faults, the hybrid beam-shell FEM model [20, 21] has been proposed (Fig. 18). The length of affected pipeline under fault movements is usually too long for a shell-mode calculation because of the limitation of memory and costly computations. Therefore, only the pipeline segment near fault is modelled with large deformation shell elements in order to consider the effect of large section deformation, and then beam elements are used to model far-fault parts of the pipeline. For reinforced linings, the bars can be accounted in the model by modifying the bulk properties of the lining.

\subsection{Prefabricated (jointed, segmented) tunnel lining}

The lining of a TBM driven (shield) tunnel consists of single precast concrete segments which are assembled at the ring (coupling, circumferential, lateral) joints and segment (longitudinal) joints. Segments are bolted together in the tangential direction to form rings, and the rings are bolted together in longitudinal direction to form the tunnel lining. Presence of joints could result in up to $50 \%$ reduction in the developed moments 
[9]. There are: straight-jointed rings (uncoupled rings, unrolled tunnel lining, sequence lining arrangement) in which case properties of a cross section such, as a position of longitudinal joints, are the same along the tunnel (Fig. 19(a)), and staggered-jointed rings (coupled rings, rolled tunnel lining, masonry layout) when properties of a cross section change at each ring, thus distribution of internal forces is also changing (Fig. 19(b)).

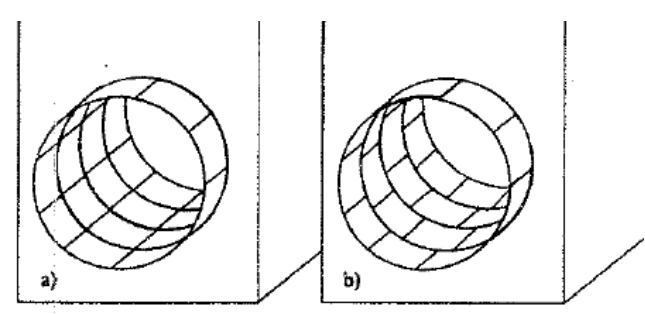

Fig. 19 Types of segmented tunnel linings

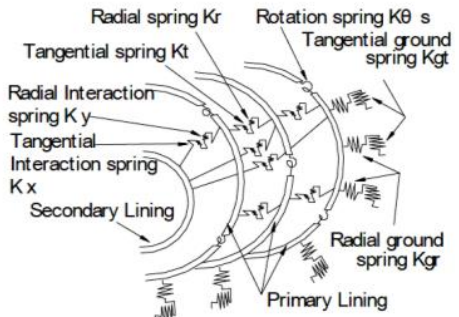

Fig. 20 Beam-spring calculation method [9]

The usual calculation method assumes that the segmental ring is a ring with uniform bending rigidity, ignoring the decrease of rigidity at segment joints [22]. For an uncoupled system of hinged rings the estimated bending moments are too high and should give conservative results [23].

In the modified usual calculation method a coefficient of effective ratio of bending rigidity $\eta \leq 1$ is introduced to evaluate rigidity of joints, and a bending rigidity is represented as $\eta E I$. In addition, a transfer ratio of bending moment $\zeta$ is introduced, the moment of main section is calculated as $(1+\zeta) M$ and the moments of the joints are calculated as $(1-\zeta) M$, where $M$ is bending moment of a uniform ring of bending rigidity $\eta E I$. The value of $\eta$ and $\zeta$ are mainly determined by experiences, which is random and uncertain [22]. The maximum bending moments calculated with this approach are quite close to the maximum bending moment calculated for a hinged uncoupled ring. For coupled rings these moments are mostly too small [23].

In the ring with multiple hinged joints calculation method segment joints are treated as hinges. The influence of ring joint is not considered, but the influence of segment joint is exaggerated [22].

Beam-spring model calculation method assumes the segmental ring as a ring with rotational and shear springs. This is a method to evaluate reduction of bending rigidity and splice effects of staggered arrangement by using a model where a segment is considered as a curved beam or a straight beam. A segment joint is as a rotational spring. A ring joint is as a coupled axial (radial) and shear (tangential) spring (Fig. 20).

Both the modified usual calculation method and the beam-spring model calculation method are quasi three-dimension methods (i.e., plane calculation methods). Their results mainly reflect the cross performance even though they can consider splice effects of staggered arrangement, and the longitudinal structure performance of tunnel is related to the cross structure performance of tunnel. Shell-spring model calculation method can reflect the more practical stress of the shield segments by a 3D-finite-element model with bedded shell elements connected with nonlinear springs [22, 23].

There are other modelling approaches: shell elements with tied freedom boundary conditions, as well as shell elements for modelling both segments and joints [11]. 


\subsection{Sprayed concrete lining}

The lining model presented in the previous section can also be applied to the modelling of sprayed concrete linings being used in NATM - New Austrian Tunnelling Method. There are no segments and joints, but the entire lining uses this special model, so cracking is permitted to develop at any location around the lining, particularly if severe distortions of the tunnel lining such under the earthquake action are expected [24].

\subsection{Composite concrete lining (primary and secondary lining)}

The parts of linings are modelled as beams. To model internal transmission of sectional forces between the linings, an interlayer modelled by a plane strain element is installed between the beams used to simulate the primary and secondary lining [25]. An alternative approach to model the interface between the primary and secondary lining is by the radial and tangential interaction springs (Fig. 20) [9]. In the analysis of El Naggar et al. [26], the tunnel lining is treated as an inner jointed thin-walled shell coupled with an outer continuous thick-walled cylinder embedded in elastic ground. The outer thickwalled cylinder can be used to simulate composite liner behaviour (e.g., tunnel supports comprising a primary and secondary lining), or to consider the influence of a degraded zone around the inner tunnel lining.

\section{MODELling THE CONTACT INTERFACE}

Interface between structural elements and soil can be modelled in a variety of ways [11]. The use of continuum elements, with compatibility of displacements, in a finite element analysis prohibits relative movement at the soil-structure interface (no-slip condition). In many soil-structure interaction situations, however, relative movement of the structure with respect to the soil can occur, i.e. slip and even separation, excluding the occurrence of penetrating an element into adjacent one (full-slip condition). Many methods have been proposed to model discontinuous behaviour at the soil-structure interface: thin continuum elements with standard constitutive laws; linkage elements in which only the connections between opposite nodes are considered (usually opposite nodes are connected by discrete springs); special interface or joint elements of either zero or finite thickness; hybrid methods where the soil and structure are modelled separately and linked through constraint equations to maintain compatibility of force and displacement at the interface. Full slip condition could also be modelled through a ring of plane strain elements with a very low shear modulus $\boldsymbol{G}$ [27]. The most accurate simulation of the soil-structure interface is by using the surface-to-surface contact model.

\section{CONCLUDING REMARKS}

The finite element method is used lately to solve complex problems regarding tunnel structures such as: simulating the construction sequences, realistic soil behaviour, complex hydraulic conditions, accounting for adjacent structures, short and long term conditions, multiple tunnels, seismic behaviour. Although it is considered the most exact calculation method, in the FEM the input data dictate the resulting output, and can be 
"wrong" even if the algorithm works properly. The modelling is subjected to six sources of errors that might lead to poor predictions: modelling the geometry of the problem, modelling of construction method and its effects, constitutive modelling and parameter selection, theoretical basis of the solution method, interpretation of results, human error. It is important to understand the behaviour of each finite element and their limitations, in order to choose the right solution for the interaction between a tunnel structure and soil.

\section{REFERENCES}

1. Zlatanović, E., "Influence of earthquakes on the stress and strain state of the shallow tunnel structures in saturated soil of low bearing capacity", Facta Universitatis: Architecture and Civil Engineering 6(2), 2008, pp. 221-227.

2. Visone, C., Santucci de Magistris, F. and Billota, E., "Comparative study on frequency and time domain analyses for seismic site response", EJGE, Vol. 15, 2010.

3. Kramer, S. L., Geotechnical Earthquake Engineering, Prentice Hall, New Jersey, 1996.

4. Ross, M., "Modelling methods for silent boundaries in infinite media", ASEN 5519-006: Fluid-Structure Interaction, Aerospace Engineering Sciences - University of Colorado at Boulder, 2004.

5. Uno, K., Shiojiri, H., Kawaguchi, K. and Nakamura, M., "Analytical method, modelling and boundary condition for the response analysis with nonlinear soil-structure interaction", $14^{\text {th }}$ WCEE, Beijing, China, 2008.

6. Gajo, A., Saetta, A., Vitaliani, R., "Silent boundary conditions for wave propagation in saturated porous media", International Journal for Numerical and Analytical Methods in Geomechanics, Vol. 20, 1996, pp. 253-273.

7. Moaveni, S., Finite Element Analysis: Theory and Application with ANSYS, Pearson Education, NJ, 2003.

8. Kuhlemeyer, R. L. and Lysmer, J., "Finite element method accuracy for wave propagation problems", Journal of the Soil Mechanics and Foundations Division, ASCE, 99(5), 1973, pp. 421-427.

9. Mizuno, K. and Koizumi, A., "Dynamic behavior of shield tunnels in the transverse direction considering the effects of secondary lining", $1^{\text {st }}$ European Conf. on Earthq. Engin. and Seismology, Geneva, Switzerland, 2006.

10. Kouretzis, G. P., Bouckovalas, G. D. and Gantes, C. J., "3-D shell analysis of cylindrical underground structures under seismic shear (S) wave action", Soil Dynamics and Earthquake Engineering 26, 2006, pp. 909-921.

11. Potts, D. M. and Zdravkovic, L., Finite Element Analysis in Geotechnical Engineering: Theory, Thomas Thelford, London, 1999.

12. Bardet, J. P., Ichii, K. and Lin, C. H., "EERA - A computer program for Equivalent-linear Earthquake site Response Analyses of layered soil deposits", University of Southern California, Los Angeles, California, 2000.

13. Hashash, Y. M. A. and Park, D., "Non-linear one-dimensional seismic ground motion propagation in the Mississipi embayment," Engineering Geology 62, 2001, pp. 185-206.

14. Yu, H.-S., Plasticity and Geotechnics, Springer Science + Business Media, LLC, New York, 2006.

15. Milutinović, Z., Engineering Seismology, International Postgraduate Program IZIIS Master Course, 2007-2008.

16. Hashash, Y. M. A. and Park, D., "Viscous damping formulation and high frequency motion propagation in non-linear site response analysis", Soil Dynamics and Earthquake Engineering 22, 2002, pp. 611-624

17. Park, D. and Hashash, Y. M. A., "Soil damping formulation in nonlinear time domain site response analysis," Journal of Earthquake Engineering 8(2), 2004, pp. 249-274.

18. Yue, Q. X. anf Li, J., "Dynamic response of utility tunnel during the passage of Rayleigh waves", $14^{\text {th }}$ World Conference on Earthquake Engineering, Beijing, China, 2008.

19. Broćeta, G., "Istraživanje komponentnih materijala samozbijajućeg betona sa metodama ispitivanja svježe betonske mase", Magistarski rad, Arhitektonsko-građevinski fakultet, Univerzitet u Banjaluci, Banjaluka, 2010.

20. Karamitros, D. K., Bouckovalas, G. D. and Kouretzis, G. P., "Stress analysis of buried steel pipelines at strike-slip fault crossings", Soil Dynamics and Earthquake Engineering 27, 2007, pp. 200-211. 
21. Halabian, A. M., Hokmabadi, T. and Hashemolhosseini, S. H., "Numerical study on soil-HDPE pipeline interaction subjected to permanent ground deformation", $14^{\text {th }}$ WCEE, Beijing, China, 2008.

22. Huang, Z., Zhu, W., Liang, J., Lin, J. and Jia, R., "Three-dimensional numerical modelling of shield tunnel lining", Tunnelling and Underground Space Technology 21, 2006, pp. 434

23. Klappers, C., Gruebl, F. and Ostermeier, B., "Structural analysis of segmental lining - coupled beam and spring analysis versus 3D-FEM calculations with shell elements", Tunnelling and Underground Space Technology 21, 2006, pp. 254-255.

24. Potts, D. M. and Zdravkovic, L., Finite Element Analysis in Geotechnical Engineering: Application, Thomas Thelford, London, 2001.

25. Karinski, Y. S., Shershnev, V. V., Yankelevsky, D. Z.,"The effect of an interface boundary layer on the resonance properties of a buried structure", Earthquake Engineering and Structural Dynamics 33, 2004, pp. 227-247

26. El Naggar, H., Hinchberger, S. D. and El Naggar, M. H., "Simplified analysis of seismic in-plane stresses in composite and jointed tunnel linings," Soil Dynamics and Earthquake Engineering 28, 2008, pp. 1063-1077.

27. Corigliano, M., Lai, C. G. and Barla, G., "Seismic response of rock tunnels in near-fault conditions," $1^{\text {st }}$ European Conference on Earthquake Engineering and Seismology, Geneva, Switzerland, 2006, Paper No. 998.

\section{NUMERIČKO MODELIRANJE U SEIZMIČKOJ ANALIZI TUNELA SA ASPEKTA INTERAKCIJE KONSTRUKCIJE I TLA}

U radu su istaknuti najznačajniji aspekti numeričkog modeliranja u seizmičkoj analizi tunela, sa posebnim osvrtom na fenomen interakcije konstrukcije sa okolnim tlom. Modeliranje problema $i$ analiza relevantnih uticaja mogu se izvršiti primenom softvera baziranih na metodu konačnih elemenata. U cilju definisanja pouzdanog $i$ efikasnog numeričkog modela, koji istovremeno treba da obuhvati kriterijume jednostavnosti i realistične prezentacije fizičkog problema, u analizama treba poći od jednostavnijih tehnika modeliranja (teorija elastičnosti, modeliranje okolnog tla elastičnim oprugama, pseudo-statička analiza) kako bi se postigao kompleksniji i realističniji model (teorija elasto-plastičnosti, metod konačnih elemenata, dinamička analiza).

Ključne reči: tunel, zemljotres, interakcija konstrukcije i tla, model sa konačnim elementima. 